\title{
Maternal and fetal outcome in patients of heart failure at a tertiary care centre
}

\author{
Neena Gupta ${ }^{*}$, Sachidanand Gupta ${ }^{2}$, A. L. Chandani ${ }^{3}$, P. Dubey ${ }^{1}$, \\ Renu Gupta', Preeti Yadav ${ }^{1}$
}

${ }^{1}$ Department of Obstetrics \& Gynaecology, ${ }^{2}$ Department of Anaesthesiology, ${ }^{3}$ Department of Medicine, G.S.V.M. Medical College, Kanpur-208002, Uttar Pradesh, India

Received: 30 October 2013

Accepted: 13 November 2013

\author{
*Correspondence: \\ Dr. Neena Gupta, \\ E-mail: neena.gupta2211@gmail.com
}

(C) 2013 Gupta $\mathrm{N}$ et al. This is an open-access article distributed under the terms of the Creative Commons Attribution Non-Commercial License, which permits unrestricted non-commercial use, distribution, and reproduction in any medium, provided the original work is properly cited.

\begin{abstract}
Background: To study maternal and fetal outcome in antenatal patients with heart failure.

Methods: The present study was conducted on pregnant female with heart failure admitted to hospital UISEMH, Kanpur from January 2012 to August, 2013. We attended 6800 pregnant female admitted to hospital out of which 48 pregnant female had heart failure during pregnancy or in labour. This was descriptive observational study.

Results: Percentage of pregnant female with heart failure in our study was $0.7 \%$. The mean of age distribution in pregnant patients with heart failure is $22.66 \pm 2.82$ years. Primigravida and primipara contributed to major group with $77.09 \%$ (37/48). Delivery was conducted in $33.3 \%$, while $60.4 \%$ were expired. $4 \%$ of cases lost follow-up. None of patient belonged to AHA class A or B of heart failure. 37.5\% were in AHA class C while 62.5\% were in class D. Early diagnosis was made in only $16.58 \%$ of cases. $75 \%$ of early diagnosed case survived in comparison to $32 \%$ of late diagnosis. $31.25 \%$ cases delivered term healthy babies, $37.5 \%$ were dead born and pre-term and small for gestation babies are $12.5 \%$ and $18.75 \%$ respectively. Of dead born $66.6 \%$ were macerated and $33.3 \%$ were fresh stillbirths. Among survivals $57 \%$ had ventilator support.

Conclusion: Early diagnosis and prompt management improves outcome. Maternal and fetal outcome is dependent on time of diagnosis, severity of heart failure and ventilator support.
\end{abstract}

Keywords: Heart failure, maternal outcome, fetal outcome

\section{INTRODUCTION}

Females have to face a very physiological condition in their life i.e. pregnancy which itself poses a significant burden on cardiovascular system due to hemodynamic changes such as cardiac output, blood volume, heart rate etc. during pregnancy and delivery. While a normal heart is quite capable of taking this extra workload right in its stride, a diseased heart may not be able to cope up with extra load or stress. Hemodynamic alteration during pregnancy:

- Decreased peripheral vascular resistance

- Decreased pulmonary vascular resistance
- Decreased colloid oncotic pressure

- Increased cardiac output

- Increased pulse rate.

Heart failure is clinical syndrome that occurs in patient who because of an inherited or acquired abnormality of cardiac structure and /or function develops a constellation of clinical symptoms (dyspnea and fatigue) and signs (edema and rales) that lead to frequent hospitalization, a poor quality of life and a shortened life expectancy. Heart failure is often a progressive condition, beginning with predisposing factors and leading to development and worsening of clinical illness. Several stages in evaluation 
of heart failure as outcome in 2013 American College of Cardiology Foundation/ American heart Association guidelines are.

Stage A: At high risk for heart failure, but without structural heart disease or symptoms of heart failure.

Stage B: Structural heart disease but without signs or symptoms of HF.

Stage C: Structural heart disease with prior or current symptoms of HF

Stage D: Refractory heart failure requiring specialized attention.

Most patients attended out hospital were in stage C or D. Heart failure in pregnancy is noted because of:

- Basics of cardiac physiology

- Underlying cardiac disease

- Pregnancy induced cardiac failure

\section{METHODS}

The present study was conducted on pregnant female with heart failure admitted to hospital UISEMH, Kanpur from January 2012 to August, 2013.

Selection of Cases: We attended 6800 pregnant female admitted to hospital out of which 48 pregnant female had heart failure during pregnancy or in labour according to underlying etiology. They were classified as those with structural cardiac defect, pregnancy induced cardiac dysfunction in peri-partum cardiomyopathy or indirect causes viz. are severe anemia, hypertensive disorder of pregnancy, sepsis and volume overload.

Plan of Study: This was descriptive observational study. A detailed history was taken and distribution was made in socio-economic status using Kuppuswamy Classification (Kuppuswamy B. Manual of Socioeconomic Status urban, Manasayan, Delhi, 1981).Further descriptive analysis was done in terms of age and parity. Patients were classified as booked or unbooked case. Proper evaluation of antenatal visits including cardiology followup was done. Symptoms especially asked were progressive dyspnoea on exertion, orthopnea, palpitation, light headache, exertional syncope, paroxysmal nocturnal dyspnea, progressive edema, nocturnal cough and anginal pain. History of known case of cardiac disease and time of diagnosis, medical and surgical treatment taken, history of rheumatic failure in childhood; cardiac failure at any time and family history of rheumatic fever was taken. Detailed obstetrical history with special emphasis on antenatal complaint and previous issues and its antenatal period to be elicited.

Signs especially looked in systemic examinations are raised jugular venous pressure, tachycardia, bilateral crepts, diastolic murmur, systolic murmur, peripheral edema, tender hepatomegaly. A thorough obstetric examination to be done. Besides routine antenatal investigation complete blood count and arterial blood gas analysis to be done. Electrocardiogram, Chest X-Ray and echocardiography are to be done for cardiac evaluation. Those with above clinical picture were diagnosed as case of heart failure and classified on the basis of time of pregnancy and underlying cause. Treatment was started in the view of heart failure with high flow $\mathrm{O} 2$ and diuretics. Those requiring ventilatory support with transferred to Medicine Intensive care unit or Anaesthesia Intensive care unit or Pulmonary medicine Intensive care unit based on ventilator availability.

Maternal outcome in terms of survival and expiry was noted and categorized among those shifted to Intensive care unit for ventilator support and those not. Fetal outcome assessment was done as dead born or live issues. Live issues were further categorized among term, preterm and small for gestation. Each etiology of heart failure during pregnancy and labor were studied for their maternal and fetal outcome.

\section{RESULTS}

To study "The Heart Failure of Different Etiology" in pregnancy \& labor" is carried out as descriptive observational study in 48 patients with heart failure admitted in indoor of Upper India Sugar Exchange Maternity Hospital affiliated to G.S.V.M. Medical College, Kanpur. Underlying direct or indirect cause of heart failure was made out and their maternal and fetal outcome was assessed.

Following conclusions were drawn from present study:

1. Percentage of pregnant female with heart failure in our study was $0.7 \%$.

2. The mean of age distribution in pregnant patients with heart failure is $22.66 \pm 2.82$ years.

3. Primigravida and primipara contributed to major group with $77.09 \%$ (37/48).

4. None of the patients was in upper class while more than half i.e. $58.33 \%$ belonged to lower socio-economic class.

5. $95 \%$ were unbooked case as most of patients were referred case. Only 2 patients had single visit, that too with no cardiology follow up.

6. Delivery was conducted in $33.3 \%$, while $60.4 \%$ were expired. $4 \%$ of cases lost follow-up.

7. None of patient belonged to AHA class A or B of heart failure. $37.5 \%$ were in AHA class $\mathrm{C}$ while $62.5 \%$ were in class D.

8. Maximum numbers of patients $(43.75 \%)$ were diagnosed during labor followed by $39.58 \%$ diagnosed during $3^{\text {rd }}$ trimester. Early diagnosis was made in only $16.58 \%$ of cases. Thus, early diagnosis and prompt management improves outcome. Patients with diagnosis of severe rheumatic heart disease must be forbidden not to conceive before surgical correction. 
9. $75 \%$ of early diagnosed case survived in comparison to $32 \%$ of late diagnosis. Conclusion is that early diagnosis improves survival.

10. $31.25 \%$ cases delivered term healthy babies, $37.5 \%$ were dead born and pre-term and small for gestation babies are $12.5 \%$ and $18.75 \%$ respectively. Of dead born $66.6 \%$ were macerated and $33.3 \%$ were fresh still-births.

11. Comparing expiry between two class of heart failure i.e. American Health Association Class C and Class D, expiry rate was $31 \%$ in former in comparison to $69 \%$ in latter. Class $\mathrm{C}$ has better prognosis than Class D.

12. Fetal outcome was also studied in both class $C$ and $\mathrm{D}$ of American Health Association differently. Term healthy babies are common in class $C(80 \%)$ while dead born are common with class D $(66.66 \%)$

13. Ventilatory support improves outcome, as among survivals $57 \%$ had ventilator support, this was strikingly contrast to only $10 \%$ of expiry of those who had ventilator support. The relationship of ventilator support to survival is statistically significant ( $\mathrm{p}$-value $<0.05$ ).

\section{DISCUSSION}

The present study was conducted in 48 antenatal patients with heart failure during a period of 20 months admitted in indoor in Upper India Sugar Exchange Maternity Hospital affiliated to G.S.V.M Medical College, Kanpur. At our centre the percentage of pregnant female with heart failure is $0.7 \%$ (48/6800). This incidence was in contrast to one previously reported by Patience Olayinka Akinwuri et al in 2010, which was $0.22 \%$. The above mentioned study was done in Nigeria from 2004-2010. We studied age-wise distribution and concluded that $62.50 \%$ were in agegroup between 20-24 years, $20.83 \%$ in age-group 25-29 years. Above mentioned study showed similar results with $70 \%$ of patients in 18-24 age groups. Our study revealed disease to be more common in primigravida and primipara $(77.09 \%)$ and $8 \%$ were in p2, only $3 \%$ belonged to group p3 or more. Results were compared with same study by Patience Olayinka Akinwuri et al in 2010 , in which $50 \%$ were primigravida. Categorisation of patients on the basis of socio-economic class was also done and studied. ${ }^{1}$ Rheumatic heart disease contributing majority of our patient was more common in low socio-economic class by Oli K et al 2009, same were result as none of patient was of upper class and middle and lower class included $20 \%$ and $80 \%$ respectively [Table 1$].^{2}$

Out of 48 all were unbooked case, and just 2 cases had prior visit. This was compared with above mentioned study in which all were unbooked case. The 2 reported cases had just single visit with no cardiology work up. In our study, $16.66 \%$ cases of heart failure were diagnosed during early periods of pregnancy i.e. first or second trimester and majority $83.33 \%$ were diagnosed in third trimester or labor. Results were comparable to previous study by Patience Olayinka Akinwuri et al in 2010, with 50\% cases diagnosed in $3^{\text {rd }}$ trimester and $30 \%$ and $10 \%$ in second trimester and post-delivery respectively [Table 2]. ${ }^{1}$

Table 1: Distribution of patients according to age group and parity \& socioeconomic status ${ }^{\dagger}$.

\begin{tabular}{|lll|}
\hline Age in Years & $\begin{array}{l}\text { No. of Cases } \\
(\mathbf{N = 4 8})\end{array}$ & $\begin{array}{l}\text { Percentage } \\
(\%)\end{array}$ \\
\hline $15-19$ & 5 & $10.42 \%$ \\
\hline $20-24$ & 30 & $62.50 \%$ \\
\hline $25-29$ & 10 & $20.83 \%$ \\
\hline$>30$ & 3 & $6.25 \%$ \\
\hline Parity & 20 & $41.67 \%$ \\
\hline P0 & 17 & $35.42 \%$ \\
\hline P1 & 8 & $16.67 \%$ \\
\hline P2 & 3 & $6.25 \%$ \\
\hline$\geq P 3$ & 0 & \\
\hline Socio-Economic Class & \\
\hline Upper* & 20 & 0 \\
\hline Middle** & 28 & $41.67 \%$ \\
\hline Lower*** & $58.33 \%$ \\
\hline
\end{tabular}

* The mean of age distribution in pregnant patients with heart failure is $22.66 \pm 2.82$ years.

${ }^{\dagger}$ Distribution was made in socio-economic status using Kuppuswamy Classification (Kuppuswamy B. Manual of Socioeconomic Status urban, Manasayan, Delhi, 1981)

* Socioeconomic class $1 * *$ Socioeconomic class $2 \& 3$

*** Socioeconomic class $4 \& 5$

Table 2: Distribution of patients of heart failure based on their time of diagnosis and number of antenatal visits.

\begin{tabular}{|llll|}
\hline \multirow{2}{*}{ Time of Diagnosis } & & \multicolumn{1}{l}{$\begin{array}{l}\text { No. of } \\
\text { Cases } \\
(\mathbf{N}=48)\end{array}$} & $\begin{array}{l}\text { Percentage } \\
(\%)\end{array}$ \\
\hline \multirow{2}{*}{ Early } & First trimester & 1 & $2.08 \%$ \\
\cline { 2 - 4 } & Second trimester & 7 & $14.58 \%$ \\
\hline \multirow{2}{*}{ Late } & Third trimester & 19 & $39.58 \%$ \\
\cline { 2 - 4 } & Labor & 21 & $43.75 \%$ \\
\hline \multirow{2}{*}{ No visits } & & Antenatal Visits & \\
\hline$<3$ visits & & 46 & $95.83 \%$ \\
\hline$\geq 3$ visits & & 2 & $4.17 \%$ \\
\hline
\end{tabular}


WA Wan Ahmad et al (2011) stated periods of greatest risk for cardiac events during pregnancy are early third trimester, delivery and immediate post-partum period. In our study, $75 \%$ of early diagnosed case survived in comparison to $32 \%$ of late diagnosis. ${ }^{3}$ In our study, $87.5 \%$ were delivered vaginally of which $28 \%$ were assisted and $72 \%$ were normal delivery, $12.5 \%$ had caesarean section for obstetric indication only. WA Wan Ahmad et al (2011) reported that outcome of peripartum cardiomyopathy in multiple small series studies have shown variable maternal mortality ranging from $12.5 \%$ to $50 \%$ with half deaths occurring within 3 months of delivery [Table 3$]^{3}{ }^{3}$

Table 3: Distribution of patient of heart failure based on their pregnancy outcome.

\begin{tabular}{|llll|}
\hline Pregnancy Outcome & $\begin{array}{l}\text { No. of } \\
\text { Cases } \\
(\mathrm{N}=48)\end{array}$ & $\begin{array}{l}\text { Percentag } \\
\text { e (\%) }\end{array}$ \\
\hline $\begin{array}{l}\text { Continuation of } \\
\text { pregnancy }\end{array}$ & 1 & $2.08 \%$ \\
\hline Lost follow-up & 2 & $4.16 \%$ \\
\hline Labor & Normal & 10 & $20.83 \%$ \\
\cline { 2 - 3 } & Assisted & 4 & $8.32 \%$ \\
\hline Expired & & 2 & $4.16 \%$ \\
\hline
\end{tabular}

Majority of patient's i.e. $60.4 \%$ expired.

American Health Association based classification is proposed in this very year, so there is no previous study to be discussed for comparison to my result. Results showed $37.8 \%$ in class $\mathrm{C}$ and $62.5 \%$ in class D [Table 4].

Table 4: Distribution of patients according to American Health Association classification of heart failure*.

\begin{tabular}{|lll|}
\hline $\begin{array}{l}\text { American Health } \\
\text { Association Class }\end{array}$ & $\begin{array}{l}\text { No. of Cases } \\
(\mathbf{N}=\mathbf{4 8})\end{array}$ & $\begin{array}{l}\text { Percentage } \\
(\%)\end{array}$ \\
\hline A & 0 & 0 \\
\hline B & 0 & 0 \\
\hline C & 18 & $37.5 \%$ \\
\hline D & 30 & $62.5 \%$ \\
\hline
\end{tabular}

*American College of Cardiology Foundation/ American heart Association guidelines (2013)

None of the patient belonged to class $\mathrm{C}$ or $\mathrm{D}$.

All patients were in NYHA (New York Health Association) class D.

Our results showed that one-third were preterm babies and small for gestational age, which is comparable to study done by Sawhney H et al (2003) where $12 \%$ were preterm $18.2 \%$ were small for gestational age. ${ }^{4}$ But quite lower than study of Hameed A et al (2001) where 23\% were preterm babies and $21 \%$ were small for gestational age. ${ }^{5}$ In a study done by Verenastangle et al (2008) preterm were $22 \%$ and SGA were $14 \%$ which is also comparable to our study. ${ }^{6}$ Paul Khairy et al 2006 in congenital heart. Adverse neonatal outcomes occurred in $25 \%$ of ongoing pregnancies and included preterm delivery $(20.8 \%)$, small for gestational age (8.3\%), respiratory distress syndrome $(8.3 \%)$, intraventricular hemorrhage $(1.4 \%)$, intrauterine fetal demise $(2.8 \%)$, and neonatal death $(1.4 \%)$ [Table 5$]^{7}$

Table 5: Relationship of maternal \& fetal outcome with early and late diagnosis.

\begin{tabular}{|lllll|}
\hline \multicolumn{5}{|c|}{ Maternal Outcome } \\
\hline N=48 & $\begin{array}{l}\text { Early } \\
\text { Diagnosis }\end{array}$ & $\begin{array}{l}\text { Percentage } \\
(\%)\end{array}$ & $\begin{array}{l}\text { Late } \\
\text { Diagnosis }\end{array}$ & $\begin{array}{l}\text { Percentage } \\
(\%)\end{array}$ \\
\hline Survived & 6 & $31.57 \%$ & 13 & $6.89 \%$ \\
\hline Expired & 2 & $68.42 \%$ & 27 & $93.10 \%$ \\
\hline \multicolumn{5}{|c|}{ Fetal Outcome } \\
\hline Term & 1 & $33.33 \%$ & 4 & $30.7 \%$ \\
\hline Preterm & - & - & 3 & $23.07 \%$ \\
\hline $\begin{array}{l}\text { Small for } \\
\text { gestation }\end{array}$ & - & - & 2 & $15.3 \%$ \\
\hline Dead born & 2 & $66.66 \%$ & 4 & $30.7 \%$ \\
\hline
\end{tabular}

Zhong Nan et al 2005 reported $38.20 \%$ cases as heart failure and $55.88 \%$ as moderate or severe heart failure. We discussed outcome on the basis categorization as per American Health Association 2013 and results depicted that survival rate is better in class $\mathrm{C}(63.15 \%)$ as compared to class D (36.84\%). Statistical analysis showed $\mathrm{p}$ - value = 0.0579 . Fetal outcome was better in class $\mathrm{C}$ No previous study was found in literature to discuss this categorized maternal and fetal outcome [Table 6]. ${ }^{8}$

Survival was better in American Health Association class $\mathrm{C}(63.15 \%)$ as compared to class D (36.84\%). Statistical analysis showed $\mathrm{p}$ - value $=0.0579$.

Survival rate in patient with ventilator support in our study is $57.8 \%$. This result is comparable to previously reported result by Poornima B et al 2013 with survival rate $64.6 \%$ and mortality rate $33.8 \%$. Only 3 cases expired despite of ventilatory support in our study [Table 7]. ${ }^{9}$

Among survivals $57 \%$ had ventilatory support, this was strikingly contrasted to only $10 \%$ of those who had ventilator and then expired. These data are statistically significant with p-value $<0.05$. 
Table 6: Maternal \& fetal outcome in patients of heart failure on the basis of American Health Association classification.

\begin{tabular}{|lllll|}
\hline \multicolumn{5}{|c|}{ Maternal Outcome } \\
\hline N=48 & $\begin{array}{l}\text { AHA } \\
\text { grade C }\end{array}$ & $\begin{array}{l}\text { Percentage } \\
(\%)\end{array}$ & $\begin{array}{l}\text { AHA } \\
\text { grade D }\end{array}$ & $\begin{array}{l}\text { Percentage } \\
(\%)\end{array}$ \\
\hline Survived & 12 & $63.15 \%$ & 7 & $36.84 \%$ \\
\hline Expired & 9 & $31.03 \%$ & 20 & $68.96 \%$ \\
\hline \multicolumn{5}{|c|}{ Fetal Outcome } \\
\hline Term & 4 & $57.14 \%$ & 1 & $11.11 \%$ \\
\hline Preterm & - & - & 2 & $22.22 \%$ \\
\hline $\begin{array}{l}\text { Small for } \\
\text { gestation }\end{array}$ & 1 & $14.28 \%$ & 2 & $22.22 \%$ \\
\hline Dead born & 2 & $28.58 \%$ & 4 & $44.44 \%$ \\
\hline
\end{tabular}

Table 7: Distribution of patients of heart failure based on their maternal outcome with ventilatory support.

\begin{tabular}{|rlll|}
\hline Maternal Outcome & $\begin{array}{l}\text { No. of } \\
\text { cases } \\
(\mathbf{N}=48)\end{array}$ & $\begin{array}{l}\text { Percentage } \\
(\%)\end{array}$ \\
\hline Survival & $\begin{array}{l}\text { with ventilator } \\
\text { support }\end{array}$ & 11 & $18.75 \%$ \\
\cline { 2 - 4 } & $\begin{array}{l}\text { without ventilator } \\
\text { support }\end{array}$ & 8 & $10.42 \%$ \\
\hline \multirow{2}{*}{ Expired } & $\begin{array}{l}\text { with ventilator } \\
\text { support }\end{array}$ & 3 & $6.25 \%$ \\
$\begin{array}{l}\text { without ventilator } \\
\text { support }\end{array}$ & 26 & $64.58 \%$ \\
\hline
\end{tabular}

Conclusion is that pregnant patient with any high risk for heart failure must have early diagnosis and managed by multidisciplinary approach at tertiary centre with ventilator support. Maternal and fetal outcome will markedly be improved with early diagnosis and efficient management.

\section{Funding: None}

Conflict of interest: None

Ethical approval: Approved by the Institutional Ethics Committee

\section{RERERENCES}

1. Patience Olayinka Akinwusi, Adetunji Oladeni Adeniji, Oluseyi, Olaboyede Atanda. Hospital-based incidence of maternal heart failure during pregnancy in Nigeria International Journal of General Medicine 2013:6 201-207.

2. Oli K, Porteous J. Prevalence of RHD among school children in Addis Ababa. East Afr Med J. 1999 Nov.;76(11):601-5.

3. W. A. Wan Ahmad, M. Khanom, Z. H. Yaakob Heart failure in pregnancy: an overview Int J Clin Pract, August 2011, 65, 8, 848- 851848 doi: 10.1111/j.1742-1241.2011.02714.x.

4. Sawhney H, Suri V, Vasishta K: Pregnancy and congenital Heart disease--maternal and fetal outcome. J Obstet Gynaecol. 1998;38(3):266-71.

5. Hameed AB, Karaalp IS, Tummala PP, Wani OR, Canetti M, Akhter MW, Goodwin I, Zapadinsky N, Elkayam $\mathrm{U}$ : The effect of valvular heart disease on maternal and fetal outcome in pregnancy. J Am Coll Cardiol 2001;37:893.

6. Verena Stangl, Johanna Schad, Gabriele Gossing, Adrian Borges Gert Baumann, Karl Stangl. Maternal heart disease and pregnancy outcome. European Journal of Heart Failure 10 (2008) 855860.

7. Paul K Hairy, David W. Ouyang, Susan M. Fernandes, PA-C; Aviva Lee-Parritz, Katherine E. Economy, Michael J. Landzberg. Pregnancy Outcomes in Women With Congenital Heart Disease Circulation. 2006; 113: 517-524 doi: 10.1161/CIRCULATION AHA.105.589655.

8. Zhong Nan Da Xue Xue Bao Yi Xue Ban. Management of Heart failure and timing of delivery in pregnancy 2005 Oct; 30 (5): 583-6.

9. Poornima B. Ramachandra Bhat, Mahesha $\mathrm{H}$. Navada, Sujaya V. Rao, and G. Nagarathna Evaluation of obstetric admissions to intensive care unit of a tertiary referral center in coastal India Indian J Crit Care Med. 2013 Jan-Feb; 17(1): 34-37. doi: 10.4103/0972-5229.112156.

DOI: $10.5455 / 2320-1770.1 j r \operatorname{cog} 20131233$

Cite this article as: Gupta N, Gupta S, Chandani AL, Dubey P, Gupta R, Yadav P. Maternal and fetal outcome in patients of heart failure at a tertiary care centre. Int J Reprod Contracept Obstet Gynecol 2013;2:661-5. 